\title{
Duodenal perforation following bile duct endoprosthesis placement
}

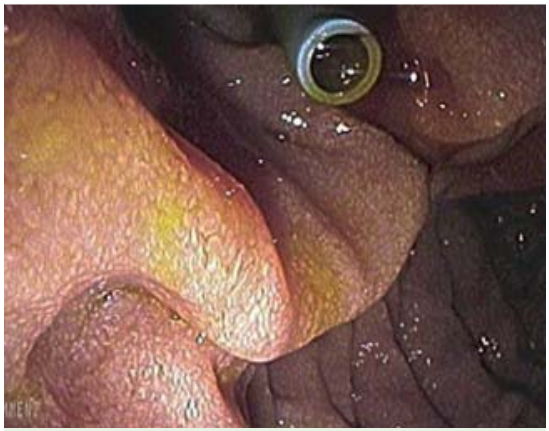

Fig. 1 Initial location of the prosthesis.

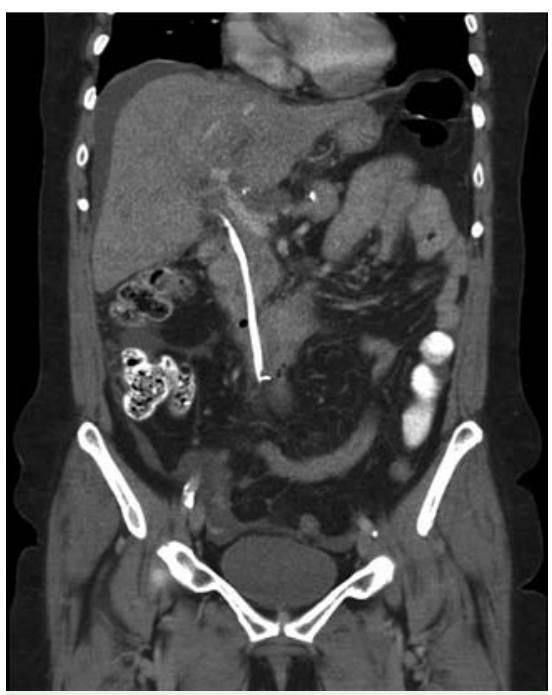

Fig. 2 Computed tomographic scan showing the prosthesis protruding well beyond the bile ducts and pressing on the duodenal wall.

A 66-year-old woman with abdominal pain and jaundice reported to our emergency department. An ultrasound examination revealed hepatic metastases with distension of the common bile duct, indicating a primary malignancy of the pancreas or bile ducts. After an unsuccessful attempt to restore bile outflow via stenting, a second endoscopic retrograde cholangiopancreatography (ERCP) was conducted. During this procedure, a stenosis of the left hepatic ducts was observed, raising suspicion of a primary malignancy of the bile ducts. Therefore, a 15-cm-long endoprosthesis was inserted in an attempt to secure the outflow of bile from the left hepatic system. The distal part of the endoprosthesis was locked in place,

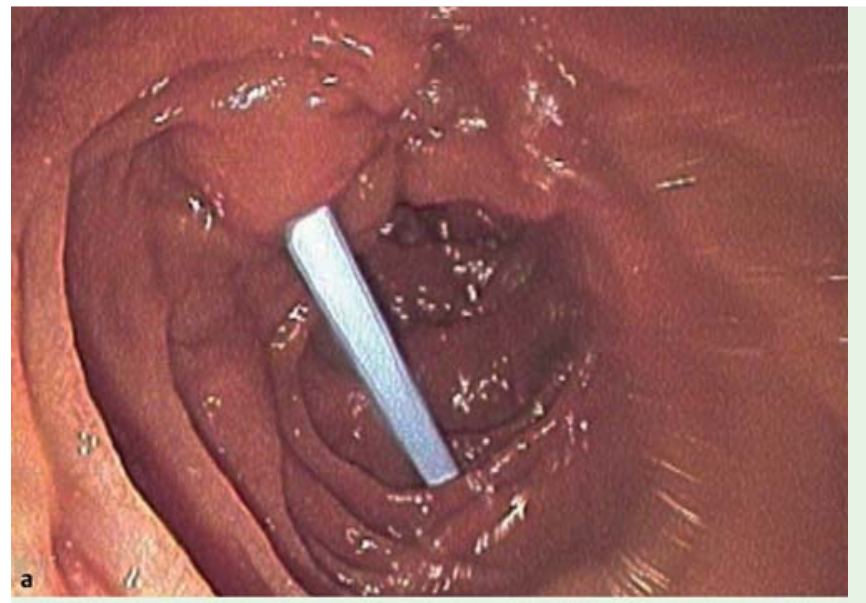

Fig. 3 a Prosthesis visible from the bile ducts and pressing into the duodenal wall before removal. b Circular puncture hole in the duodenal wall exactly matching the width of the prosthesis following removal.

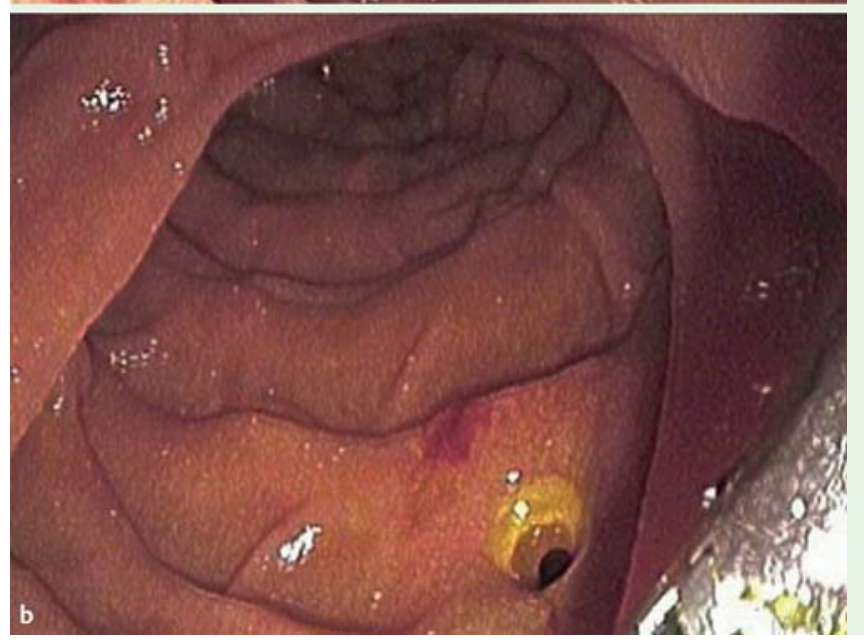

just external to the papilla ( $\bullet$ Fig. 1). Initial improvement during the first 2 days was quickly followed by the return of severe abdominal discomfort. Computed tomography revealed intra-abdominal fluid but no signs indicating a duodenal perforation, such as intra- or retroperitoneal air or retroperitoneal fluid collections ( Fig. 2). Interestingly, drained abdominal fluid was found to resemble bile closely. A third ERCP showed the endoprosthesis penetrating the duodenal wall and acting as a plug, thus explaining the absence of intra-abdominal air and the bile-like characteristics of the abdominal fluid ( Fig.3). Possibly the high pressure on the endoprosthesis caused by the malignant process pushed it toward the duodenal wall, after which it penetrated the wall. The endoprosthesis was removed and the perforation sealed with endoclips; contrast was then applied adjacent to the duodenum to evaluate the seal ( $\bullet$ Fig.4).

In general, sphincterotomy, a major risk factor for perforation, is the most common cause of perforation, which in these cases is often retroperitoneal [1-3]. In contrast, here we report an intra-abdominal perforation that occurred several days following the placement of an endoprosthesis. Finally, the aforementioned perforation was closed with endoclips. It has previously been reported that duodenal wall perforations can be treated with endoscopic clipping if this is deemed feasible [4-8].

Endoscopy_UCTN_Code_CPL_1AK_2AD

\section{Competing interests: None}




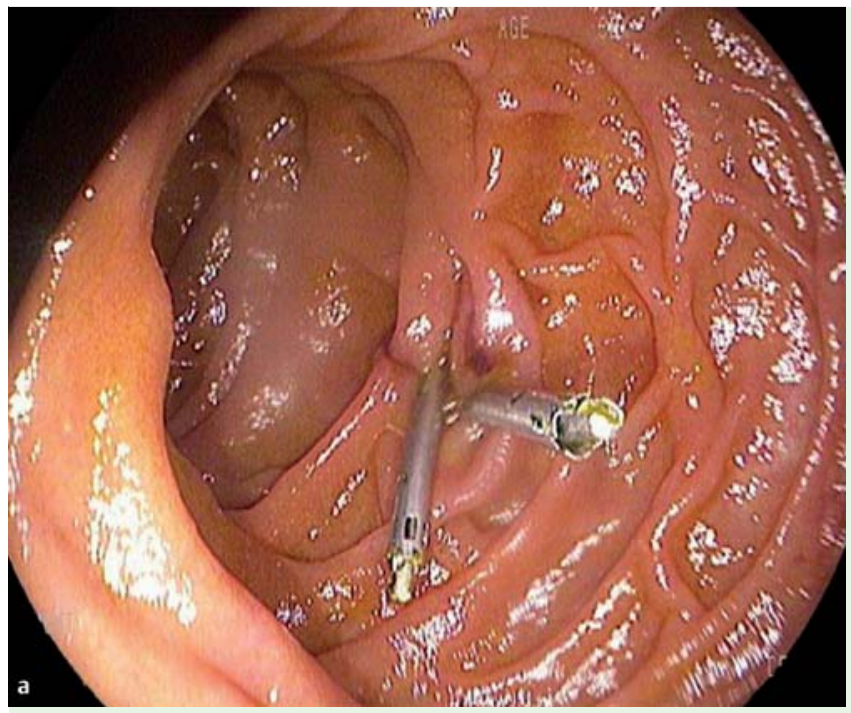

Fig. 4 a Endoscopic clipping of the perforation. $\mathbf{b}$ Absence of contrast leakage from the duodenum following endoscopic clipping.

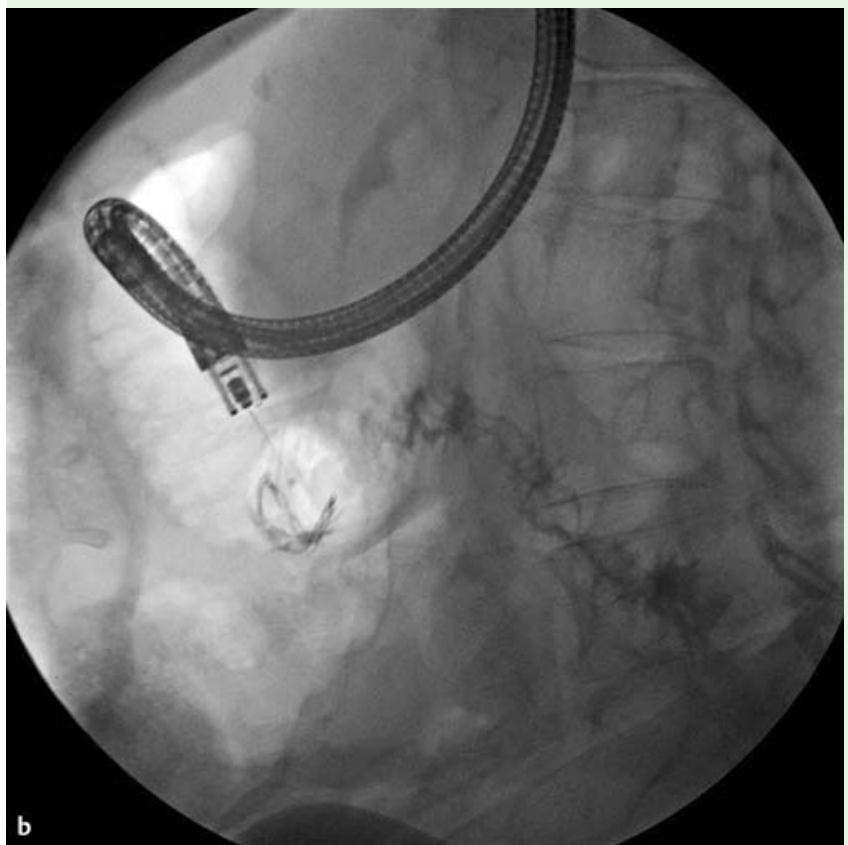

Pascal J. H. Kusters ${ }^{1,2}$, Eric T. P. Keulen, Frank P. J. Peters ${ }^{1}$

${ }^{1}$ Orbis Medical Centre, Sittard,

The Netherlands

2 Department of Medical Biochemistry, Academic Medical Center, University of Amsterdam, the Netherlands

\section{References}

1 Kahaleh $M$, Freeman $M$. Prevention and management of post-endoscopic retrograde cholangiopancreatography complications. Clin Endosc 2012; 45: 305-312

2 Mergener K. Complications of endoscopic and radiologic investigation of biliary tract disorders. Curr Gastroenterol Rep 2011; 13 : $173-181$

3 Enns R, Eloubeidi MA, Mergener Ket al. ERCPrelated perforations: risk factors and management. Endoscopy 2002; 34: 293-298

4 Seibert $D G$. Use of an endoscopic clipping device to repair a duodenal perforation. Endoscopy 2003; 35: 189

5 Sebastian S, Byrne AT, Torreggiani WC et al. Endoscopic closure of iatrogenic duodenal perforation during endoscopic ultrasound. Endoscopy 2004; 36: 245

6 Lee TH, Bang BW, Jeong JI et al. Primary endoscopic approximation suture under cap-assisted endoscopy of an ERCP-induced duodenal perforation. World J Gastroenterol 2010; 16: 2305-2310

7 Kwon CI, Song SH, Hahm KB et al. Unusual complications related to endoscopic retrograde cholangiopancreatography and its endoscopic treatment. Clin Endosc 2013; 46: 251-259

8 Kwon W, Jang JY, Ryu JK et al. Proposal of an endoscopic retrograde cholangiopancreatography-related perforation management guideline based on perforation type. J Korean Surg Soc 2012; 83: 218-226

Bibliography

Dol http://dx.doi.org/

10.1055/s-0034-1390849

Endoscopy 2014; 46: E646-E647

(c) Georg Thieme Verlag KG

Stuttgart · New York

ISSN 0013-726X

Corresponding author

\section{Pascal Kusters, MD}

Department of Internal Medicine

Orbis Medical Centre

Dr. H. van der Hoffplein 1

Sittard-Geleen 6162 BG

The Netherlands

Fax: 0884597983

p.kusters@gmail.com 